\title{
Adsorption Studies of Enalapril Maleat in Solution on Selected Iraqi Clays
}

\author{
Reem. A. Al-Bayati \\ Chemistry Department / College of Science / AL-Mustansirya \\ University, Baghdad, Iraq \\ E-mail: Dr.Reem2000@yahoo.com \\ Athraa.S. Ahmed \\ Chemistry Department / College of Science / AL-Mustansirya \\ University, Baghdad, Iraq \\ E-mail: Athraa.Salman@yahoo.com
}

Received: February 28, 2011 Accepted: March 18, $2011 \quad$ doi:10.5539/ijc.v3n3p134

\begin{abstract}
The possibilities of using locally available two Iraqi clays kaolin and attapulgite are have been investigated for adsorption of model drug solution of enalapril maleate. U.V. spectrophotometric technique has been utilized to produce quantitative adsorption data at different temperatures. The effect of acidity on the quantity adsorbed of this drug was investigated at $\mathrm{Ph}=1.2$ in an attempt to simulate the acidity of gastric fluid and at neutral $\mathrm{pH}$. The possible effect of ionic strength on the amount of drug being adsorbed was studied using normal saline at different concentrations. The equilibrium adsorption contact times were determined for both two adsorbents used adsorption isotherms have been analyzed by the Freundlich and Langmuir models. The results of these studies demonstrated that enalapril maleate is adsorbed by both kaolin and attapuligate surfaces, and these two surfaces can be used as a physical antidotes against poisoning by the above drug overdose in vitro.
\end{abstract}

Keywords: Kaolin, Attapuligate, Enalapril maleate adsorption, Adsorption isotherms

\section{Introduction}

Drug The large number of acute accidental drugs ingestion, has caused considerable interest to be focused on agents that can inhibit the absorption of ingested drugs, either by causing emeses and there by removal of unabsorbed drug from the stomach or by adsorbing or sequestering drug in the gastrointestinal tract, so that the bound drug cannot be absorbed. Orally given adsorbents like (activated charcoal, kaolin, bentonite, etc) are used to bind drugs (toxins) that has not been removed by other methods (emesis or lavage) $(1,2)$. The treatment of acute poisoning by drug over dosage in general depends on the prevention of further absorption of the drug, using a specific antidotes, and acceleration of elimination of the drug (3).

Adsorbents (like activated charcoal, kaolin, attapuligate, etc.) given as a suspension in water can be usefully used when emesis and gastric lavage are contraindicated. It can bind many poisons in the stomach and so reduce their absorption (4).

Enalapril maleate is an ACE inhibitor (Angiotensin-Converting Enzyme Inhibitors) used in the treatment of hypertension and heart failure (5). There have been reports of over dosage with enalapril maleate, the main adverse effect of hypotension. This usually responds to supportive treatment and volume expansion. Activated charcoal may be given in sever over dosage if the patient present with one hour of ingestion $(6,7)$.

Due to that the aim of the research is: a) to compare the adsorption ability of both natural minerals, b) to find the most appropriate isotherm describing the most adsorption process, c) to examine the influence of temperature, $\mathrm{pH}$ and ionic strength of the solution on the adsorption of enalapril maleate as a model drug solution on both clay surfaces. 


\section{Experimental Studies}

\subsection{Materials and Methods}

The drug employed in this study (enalapril maleate) is from DSL chemicals. The absorption maximum noticed for this drug is $=215 \mathrm{~nm}(4)$, and the chemical structure is shown in figure (1).

The natural attapuligate is from (Akkashatt) area in the western desert. It was collected from an opened mine exposed to the ambient atmosphere. The chemical composition of average probe by weight $\%$ is the following: $\mathrm{SiO}_{4}-44.66 \%, \mathrm{Al}_{2} \mathrm{O}_{3}-13.36 \%, \mathrm{CaO}-13.71 \%, \mathrm{Fe}_{2} \mathrm{O}_{3}-4.2 \%, \mathrm{MgO}-3.2 \%, \mathrm{SO}_{3}-0.23 \%$.

The natural kaolin is from (Dwaikhla) opened mine (North of Rutba) in the western desert. The main chemical components of kaolin are the following: $\mathrm{SiO}_{2}-54.68 \%, \mathrm{Al}_{2} \mathrm{O}_{3}-30.19 \%, \mathrm{Fe}_{2} \mathrm{O}_{3}-1.02 \%, \mathrm{TiO}_{2}-1 \%$.

Both two clays were supplied in the powder forms. They were washed with an excessive amount of distilled water to remove the soluble materials. They were dried in the oven (Hot Air Oven, yamato Dp61, Japan) at $\left(160{ }^{\circ} \mathrm{C}\right)$ for 3 hours and kept in airtight containers. The clays have been ground and sieved (Electrical sieve, Retsoh Gmb \& Co-KG, Germany). The particle size of 125 micrometer was obtained and used for the two clays in the experiments of this work. The necessary concentrations of enalapril maleate are obtained by dilution with distillated water. The time required for full saturation of adsorbent surface at $37.5{ }^{\circ} \mathrm{C}$ by the adsorbate has been determined as follow: an initially fixed concentration $\left(5 \times 10^{-3} \mathrm{M}\right)$ of drug solution was shaken using thermo stated water bath shaker (BS.11 digital, JEI, TECH, Korea, $(20-185) \mathrm{rpm}$, with $(0.5 \mathrm{~g})$ of each adsorbent separately. Rotation was then stopped (when the time of equilibrium was reached) and the solution was then filtered by using double filter papers (Whatman No. 42, Germany). The concentration of drug solution were determined spectrophotometrically (100 Conc. / VARIAN, USA) at different time intervals from (5 to 120 minutes) until reaching equilibrium (no further uptake of adsorbate by adsorbent as the time proceeds). To obtain adsorption isotherms for each pair of adsorbent - adsorbate systems: solution of different concentrations for this drug were prepared by serial dilutions in the range of $\left(2 \times 10^{-5}-2 \times 10^{-4} \mathrm{M}\right)$ was shaken with $(0.5 \mathrm{~g})$ of adsorbent at $37.5^{\circ} \mathrm{C}$ in the shaker. Each sample was weighed by using electrical balance (Sartorius CE, Germany).

The $\mathrm{pH}$ Values of the solutions were determined with (HM-73, TDA Electronics Ltd) $\mathrm{pH}$ meter and were modeled with solutions of $\mathrm{HCl}$. After the equilibrium time elapsed, the mixtures were allowed to settle and the clear liquids were either centrifuged at $3000 \mathrm{rpm}$ for 20 minutes (Hettich Universal (D-7200), Fed- Rep of Germany) or filtered using double filter papers. The two methods of separation gave identical results. The clear supernatants were assayed for drug spectrophotometrically after the appropriate dilution.

The adsorbed amount of the drug was calculated from the concentration in solutions before and after adsorption according to the equation (1):

$$
\mathrm{Q}_{\mathrm{e}}=\left(\mathrm{C}_{\mathrm{o}}-\mathrm{C}_{\mathrm{e}}\right) \mathrm{V} / \mathrm{W}
$$

$\mathrm{Q}_{\mathrm{e}}$ : the equilibrium drug concentration on adsorbent ( $\left.\mathrm{mol} / \mathrm{g}\right)$.

$\mathrm{C}_{\mathrm{o}}$ : the initial concentration $(\mathrm{mg} / \mathrm{L})$.

$\mathrm{C}_{\mathrm{e}}$ : the equilibrium concentration $(\mathrm{mg} / \mathrm{L})$.

$\mathrm{V}$ : the volume of drug solution (L).

W: the weight of adsorbent $(\mathrm{g})$.

\section{Results and Discussion}

\subsection{Adsorption of drug by kaolin and attapuligate}

Adsorption of enalapril maleate by kaolin and attapuligate was studied. The concentrations, both before the additional of surfaces (in separate way) and after the attainment of adsorption equilibrium, were determined spectrophotometrically.

The applicability of Langmuir and Freundlich adsorption isotherms has been investigated for these adsorption systems using the equations $(2)$ and $(3)(8,9)$.

$$
\text { Langmuir isotherm }=\frac{\mathrm{X}}{\mathrm{m}} \frac{\mathrm{k}_{1} \mathrm{k}_{2} \mathrm{Q}_{\mathrm{e}}}{1+\mathrm{k}_{2} \mathrm{c}_{\mathrm{e}}}
$$




$$
\text { Freundlich isotherm } \mathrm{Q}=\frac{\mathrm{X}}{\mathrm{m}} \boldsymbol{k} \boldsymbol{c}^{p}{ }_{e}
$$

Where (x) is the amount of solute adsorbed, (m) is the mass of the adsorbent, (Ce) is the concentration of the unadsorbed solute at equilibrium, (k1) is the capacity constant, and (k2) is the affinity constant. And for Freundlich equation the $(\mathrm{k})$ is a constant related to the capacity of the adsorbent for the adsorbate and $(\mathrm{p})$ is a constant related to the affinity of the adsorbent for the adsorbate. Adsorption results indicated full applicability of Freundlich adsorption isotherm for enalapril maleate adsorption systems as given by linear relation ships obtained when $\log \mathrm{Qe}$ is plotted versus $\log (\mathrm{Ce})$ values as shown in Figure (2) and (3).

\subsection{Influence of PH of solution on the adsorption systems}

The experiments were realized at the following conditions:

Temperature $-37.5{ }^{\circ} \mathrm{C}, \mathrm{pH}=1.2$ and neutral $\mathrm{pH}$, contact time- 2 hours for attapuligate and 2.5 hours for kaolin and size of both of the two used clays particles $-125 \mu \mathrm{m}$.

The low values of $\mathrm{pH}$ are reached by acidification with HCL solution. The effect of $\mathrm{pH}$ or the solution upon the adsorption of enalapril maleate is indicated in figures (4) and (5). The change of the remaining concentrations of the drug in function from $\mathrm{pH}$ of the solutions has been followed. It can be seen from the figures, for the kaolin, the adsorption of the drug was increase with decreasing the $\mathrm{pH}$ values.

The attraction between the surface and the drug molecules at $\mathrm{pH}=1.2$ may be specific and stronger than that attraction between solvent - solute leading to an increase in the quantity adsorbed (10).

While the adsorption of the same drug on attapuligate clay showed an opposite behavior. The result indicated an increase in adsorption uptake of the drug with increasing the $\mathrm{pH}$ values. At low $\mathrm{pH}$ a competition exelred by the hydronium ions is expected to cause a significant reduction in adsorption of the drug (11). The increase in adsorption quantity of enalapril maleate with increasing $\mathrm{pH}$ of solution could be attributed to the possible changes in properties of the clay surface $(12,13)$. It was suggested that a marked increase in the adsorption of some drugs onto attapuligate with increasing $\mathrm{pH}$ value, is due to an increase in density of the negative charge on the edges of attapuligate particles (12).

\subsection{Influence of ionic strength on the drug adsorption on the two clay surfaces}

The effect of additions of physiological saline solution at two different concentration ( 0.01 and $0.05 \mathrm{M}$ of Nacl) on the adsorption of enalapril maleate on attapuligate and kaolin clays has been studied. Figures (6) and (7) show the influence of ionic strength on the amount of drug adsorption by the two clays at neutral $\mathrm{pH}$ and $37.5{ }^{\circ} \mathrm{C}$, an overall increase in drug uptake with increasing electrolyte concentration (and hence the ionic strength). This behavior may be due to the reduction in adsorbate solubility as a result of higher interaction of electrolyte ions with the aqueous solvent. Moreover, the physical properties of the clay adsorbent may change in the presence of ions in solution as consequence of electro - static interactions (14). The solubility of ionic salts in aqueous media is normally higher than that of organic drug molecules (15). Therefore, a competition between them to interact with the solvent molecules leads to an increase in the attraction between the clay surface and the drug molecules which in turn will decrease the solvent - drug interaction (16).

\subsection{Effect of Temperature}

The adsorption of the drug used on kaolin and attapuligate clays at three different temperatures has been carried out. As shown in figures (8) and (9), the adsorption extent of enalapril maleate on both two clays has no significant differences found in the amount of the drug at the different temperatures. It has been exhibited that the adsorption of this drug is of limited influenced with the increasing temperature in the studied range $\left(20-43{ }^{\circ} \mathrm{C}\right)$. That can be explained depending on clays properties and the nature of the adsorbate indicating the possibility of formation strong interactive forces between the adsorbent and the adsorbate, as the clays used consider of the highly colloids clays. Moreover, the possibility of the clay in saving solution inside its internal layers because of its highly plasticity and collidlity would give diffusion property of materials in these surfaces. Therefore, the increasing in temperature in the selected range showed a limit effect in these two clays adsorption for this drug especially at higher concentration from solution.

\section{Conclusion}

1- The Iraqi natural adsorbents kaolin and attapuligate can be used for recovering enalapril maleate with concentration between $\left(1-5 \times 10^{-5} \mathrm{mg} / \mathrm{dm}\right)$ in aqueous solution. Both natural minerals have good adsorption properties towards this drug with little superiority of attapuligate. 
2- Due to higher activity of kaolin and attapuligate surfaces in adsorption of this drug there may be used as antidotes for treatment of a cute poisoning by this drug if taken in dosages greater than the therapeutic quantities.

3- The adsorption isotherms of this drug on kaolin and attapuligate obeyed Freundlich isotherm as the adsorption increases with increasing the concentration at equilibrium. This result indicated the surface heterogeneity leading to different adsorption forces from site and different affinities towards drug molecules.

4- The $\mathrm{pH}$ and ionic strength co significantly affect the adsorption process of this drug on these two surfaces.

\section{References}

Aw. Adamson. (1997). The Solid- Liquid Interface In: physical chemistry of surfaces. edited by: ed. Adamson Aw and Gost AP; 6th edition, John Wiely and Sons, Inc: New York; 394.

British Pharmacopoeia CD-ROM. (2002). Monograph Medicinal and Pharmaceutical Substances, Vol.1.

Casarett and Doull. (1986). Toxicology; the basic science of Poisons, 3rd edition, PP: 621-840.

D.G Hollander. (1980). J.Chem. Soc. Frarday Trans, 76, 386.

D.L. Sorby, E.M. plein, J.D, Benmaman. (1966). Adsorption of phenothiazine derivatives by solid adsorbents., $J$. Pharm. Sci. 55, 785-794.

DE. Newby, et al. (1995). Enalapril overdose and corrective effect of interavenous angiotensin 11.Br. J. Clin. Pharmacol, 40: 4-103.

E., Chilvers, J., Hunter, and A., Nicholas. (1999). Davidson's principles and Practice of Medicine, 18th edition, PP: $1110-1120$.

Goth, "Medical pharmacology", 11th ed., the C.V. Mosby company, Toronto PP.: 721-72.

JJ. Kipling. (1965). Adsorption of Solids from solution" and "Adsorption at the Liquid - Solid Interface" In: Adsorption from solutions of Non- electrolytes. Academic Press, Inc: London.

M.L., Haddad, and F.J., Winchester. (1983). Clinical Management of Poisoning and Drug overdose, W.B. Saunders Co, USA, P: 162.

N.A. Armstrong and C.D. Clark. (1973). Influence of Solution electrolyte content and dielectric constant on drug adsorption by kaolin, J. Pharmy Sci, 62: 379-382.

N.A. Armstrong and C.D. Clarke. (1971). The adsorption of crystal violete by kaolin., J.Pharm. Pharmac., 23: 95s- 100s.

N.A. Armstrong and C.D. Clarke. (1976). Adsorption sites of kaolin, J. Pharm, Sci., 65 (3); 373-375.

O. AL-Gohary, J.Lyall and J.B.Murry. (1988). Adsorption of antihypertensives by suspensions, part 11: the adsorption of acebutolol,metoprolol,nadolol,oxprenolol and timolol by attapulgite, charcoal, kaolin and magnesium trisilicate, Pharm. Acta, Helv, 63 (1): 13-18.

R.H.S. Rebertson. (1973). silicates. Ind., 38, 33.

T., Jackson. (1993). Enalapril overdose treated with angiotensin infusion, lancet, 341: 703.

T.McMurry and C.F. Robert. (2001). Chemistry, 3rd edition, Prentice Hall, New Jersey, P.511.
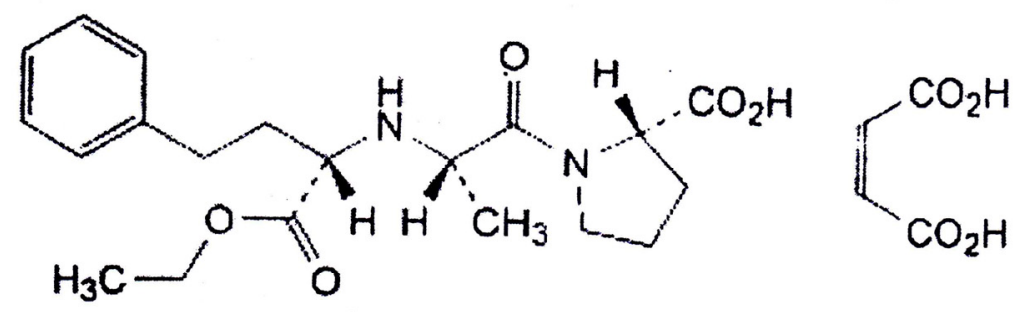

Figure 1. The Enalapril Maleate Structure 


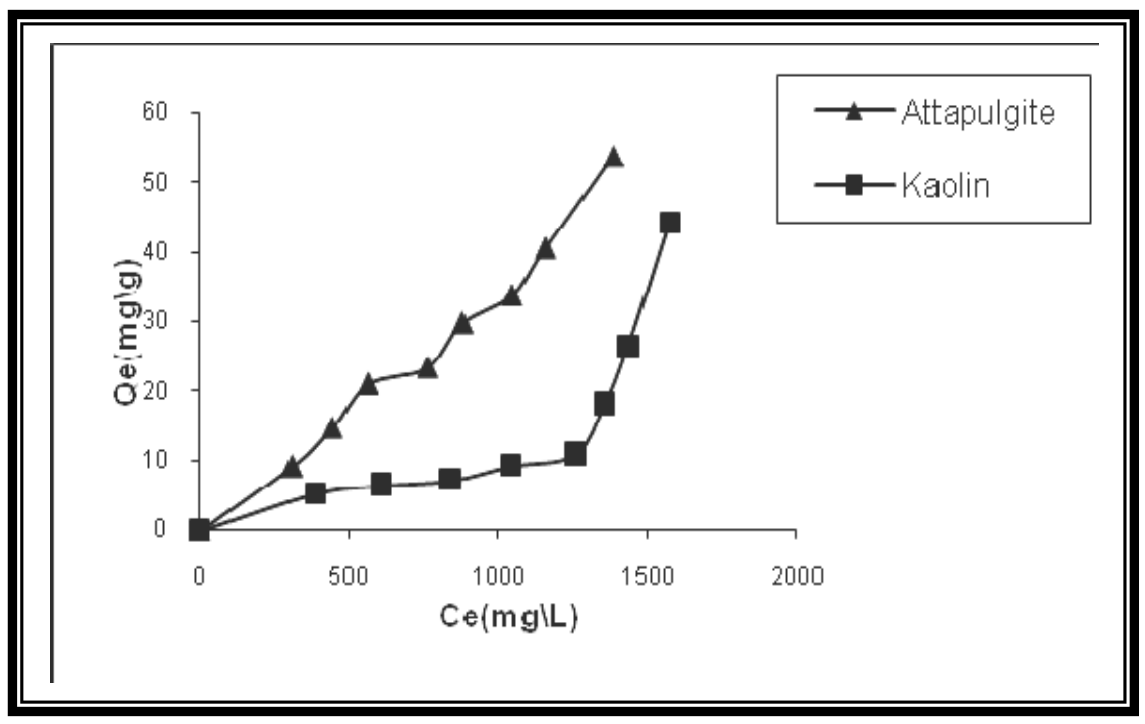

Figure 2. Adsorption isotherms of the drug on kaolin and attapuligate surfaces at $37.5{ }^{\circ} \mathrm{C}$

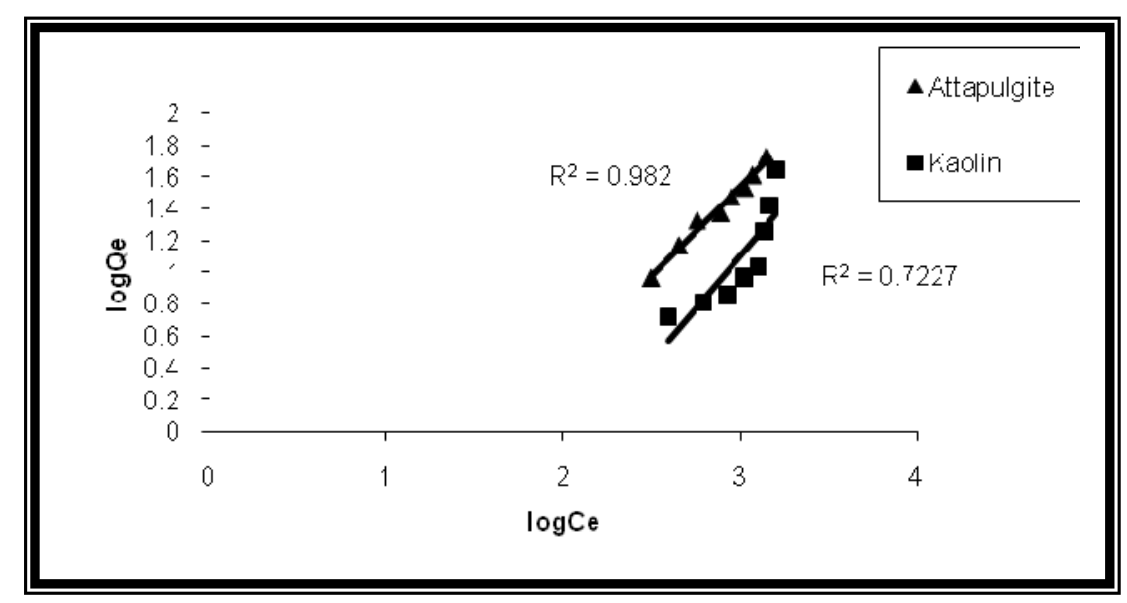

Figure 3. Freundlich lines of the adsorption of enalapril maleate on kaolin and attapuligate

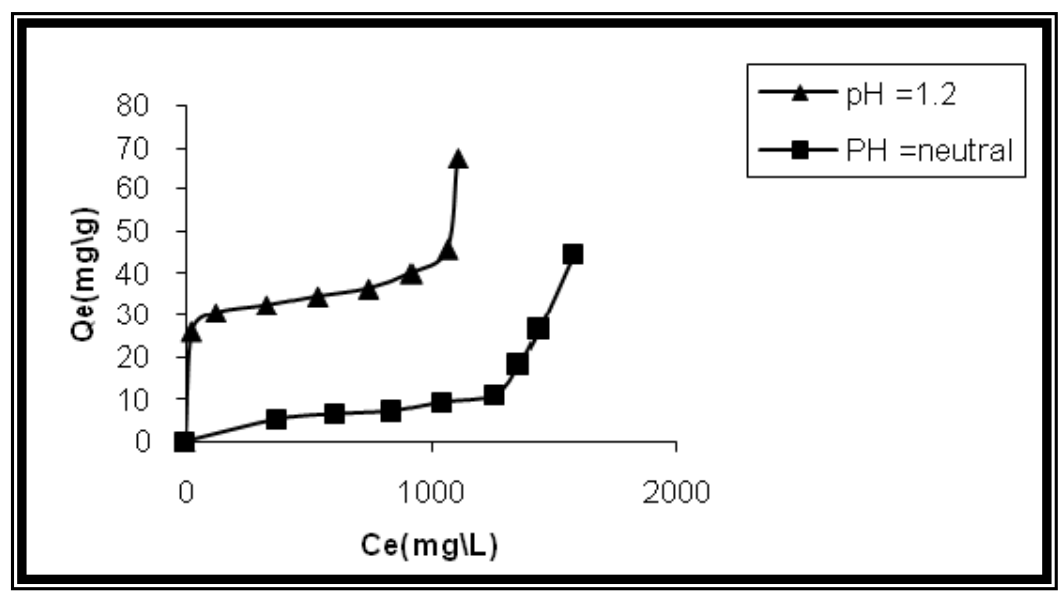

Figure 4. Influence of $\mathrm{pH}$ on the adsorption of enalapril maleate on kaolin surface 


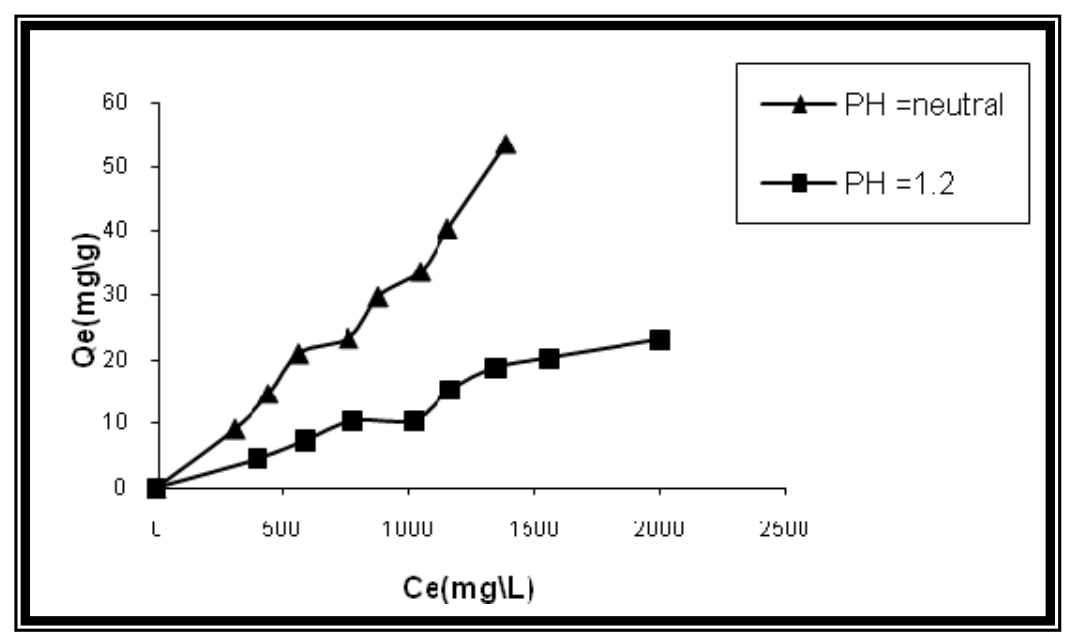

Figure 5. Influence of $\mathrm{pH}$ on the adsorption of enalapril maleate on attapuligate surface

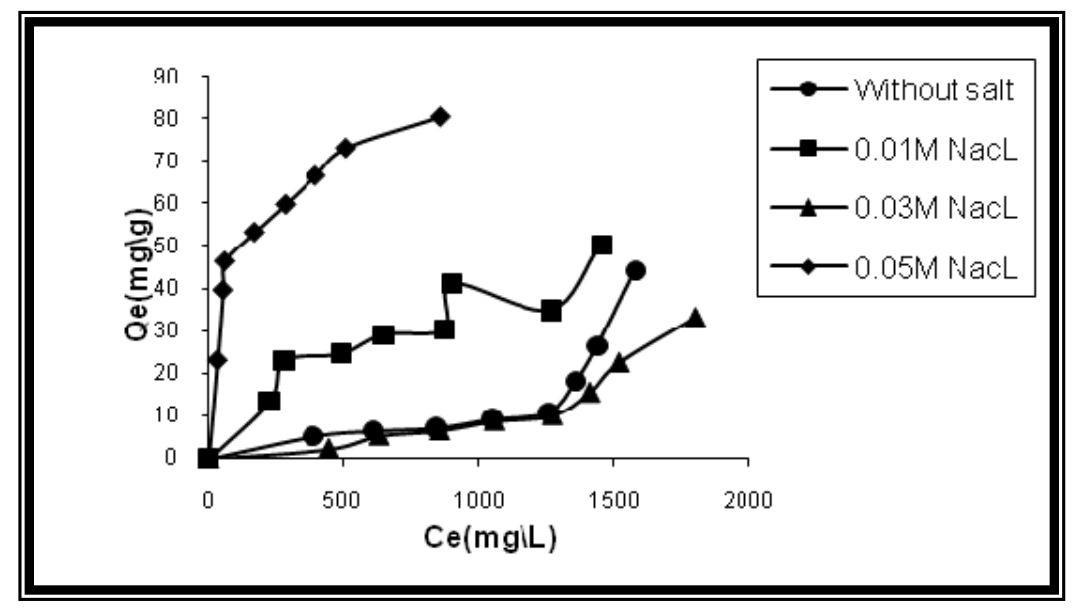

Figure 6. Effect of ionic strength on adsorption of the drug on kaolin clay at $37.5^{\circ} \mathrm{C}$ in neutral $\mathrm{pH}$

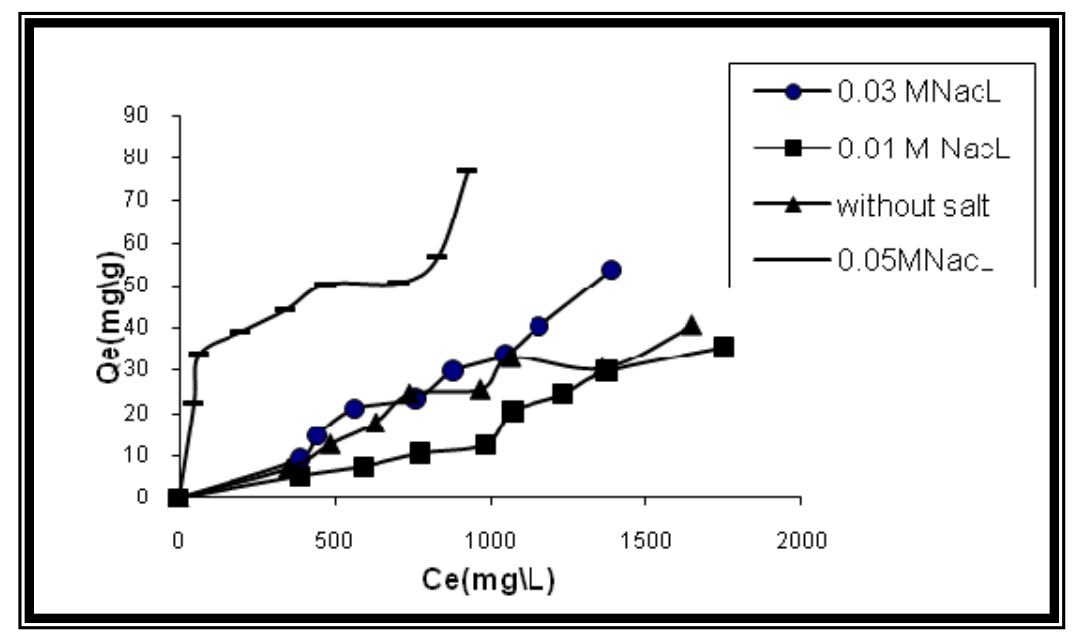

Figure 7. Effect of ionic strength on adsorption of the drug on attapulgite clay $37.5{ }^{\circ} \mathrm{C}$ in neutral $\mathrm{pH}$ 


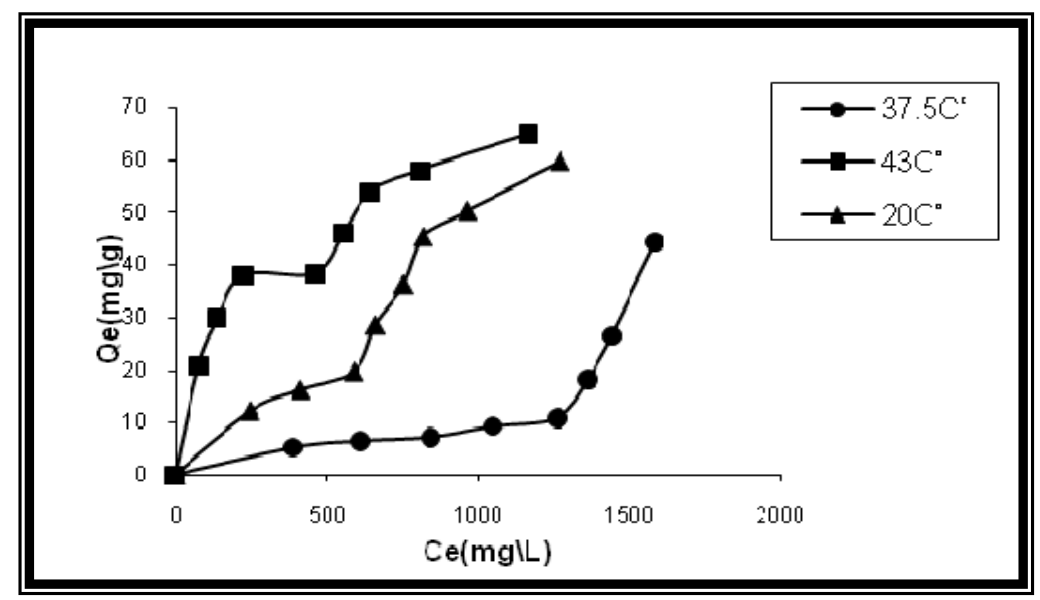

Figure 8. Adsorption isotherm of the drug on kaolin surface at different temperature

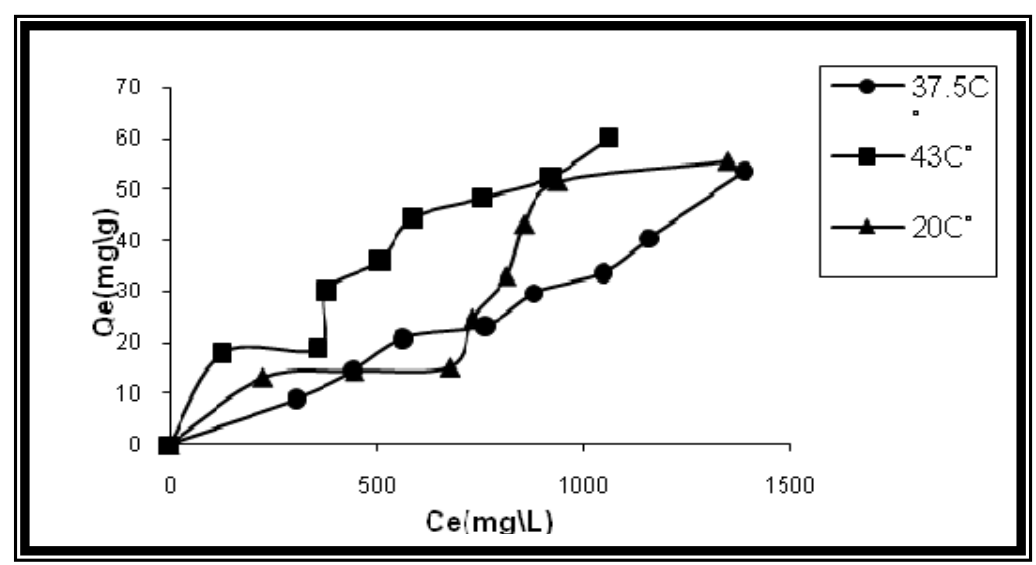

Figure 9. Adsorption isotherm of the drug on attapuligate surface at different temperature 